\title{
Milk oral immunotherapy-effective but still experimental
}

\author{
Marita Paassilta $\cdot$ Susanna Salmivesi $\cdot$ Matti Korppi
}

Received: 20 September 2012 / Accepted: 17 October 2012 /Published online: 30 October 2012

(C) Springer-Verlag Berlin Heidelberg 2012

We read with interest the paper of Alvaro et al. [1] on milk oral immunotherapy (OIT) in 66 schoolchildren aged 5-16 years with cow's milk allergy (CMA). During pretreatment placebo-controlled milk challenge, 44 had anaphylactic symptoms, and among them, 35 achieved complete $(>200 \mathrm{ml}$ milk daily) and 7 partial desensitization $(<200 \mathrm{ml})$ after 23 - to-26-week OIT. The respective figures for those 22 with non-anaphylactic symptoms were 6 and 16. One year later, still 64/66 children tolerated milk, $77 \%>150 \mathrm{ml}$. As the authors discussed, the number of children was large, and the success rate was good (96-100\%) also in children with anaphylactic symptoms [1], but the study was not controlled.

There are two randomized, placebo-controlled, doubleblind studies on OIT in schoolchildren with CMA documented with milk challenge before therapy $[2,3]$. Skripak et al. allocated 12 schoolchildren into treatment and seven into placebo arms [3]. Children with anaphylactic symptoms were excluded. Before OIT, the cow's milk threshold was $40 \mathrm{mg}$ milk protein. After OIT, the median threshold was

\footnotetext{
M. Paassilta $\cdot$ S. Salmivesi

Allergy Center, Tampere University Hospital,

Tampere, Finland

M. Korppi $(\bowtie)$

Pediatric Research Center, Tampere University

and University Hospital,

FM-3 Building,

33014 Tampere, Finland

e-mail: matti.korppi@uta.fi
}

$5,140 \mathrm{mg}(>2,540 \mathrm{mg})$ in the treatment and $40 \mathrm{mg}$ in the placebo group.

In our recent randomized, placebo-controlled, doubleblind OIT study with protein target $6,400 \mathrm{mg}(200 \mathrm{ml}$ milk) at week 23 [2], 18 schoolchildren were allocated into treatment (16 completed) and 10 into placebo arms ( 8 completed). Ten children with anaphylactic symptoms were included. After double-blind OIT, all 10 children in the placebo arm completed successfully open-label OIT. Shortterm and long-term ( 3 years) success rates were 86 and $79 \%$, respectively.

We agree with Alvaro et al. that 6-month OIT effectively induces desensitization in schoolchildren with CMA including those with anaphylactic symptoms. However, reactions are common and severe reactions are possible. This treatment is still experimental, and all children treated with OIT should belong to prospective studies, preferably to randomized, placebo-controlled, double-blind trials.

\section{References}

1. Alvaro M, Giner MT, Vázquez M, Lozano J, Domínguez O, Piquer $M$ et al (2012) Specific oral desensitization in children with IgEmediated cow's milk allergy. Evolution in one year. Eur J Pediatr 171:1389-1395

2. Salmivesi S, Korppi M, Mäkelä MJ, Paassilta M (2012) Milk oral immunotherapy is effective in school-aged children. Acta Paediatr. doi:10.1111/j.1651-2227.2012.02815.x

3. Skripak JM, Nash SD, Rowley H, Brereton NH, Oh S, Hamilton RG et al (2008) A randomized, double-blind, placebo-controlled study of milk oral immunotherapy for cow's milk allergy. J Allergy Clin Immunol 122:1154-1160 